\title{
Efecto de la suplementación de proteína y energía sobre la producción láctea, densidad, sólidos totales, grasa y nitrógeno ureico en la leche de vacas Brown Swiss en condiciones hipobáricas naturales
}

\author{
Effect of protein and energy supplementation on milk yield, density, total solids, fat \\ and milk urea nitrogen in Brown Swiss cows under natural hypobaric conditions
}

\author{
Berly Cahuascanco-Quispeㄹ, Francisco H. Rodríguez-Huanca', Marcelino J. Araníbar ${ }^{1,2}$
}

\section{Resumen}

\begin{abstract}
El estudio tuvo como objetivo determinar el efecto de la ratio energía / proteína de las raciones alimenticias suplementarias (RAS) sobre la producción y características de la leche en condiciones hipobáricas naturales (4300 m de altitud en Puno, Perú). Se distribuyeron al azar 24 vacas Brown Swiss de primer y segundo tercio de lactación en tres RAS con tres ratios de energía metabolizable / proteína (RAS1: $17.0 \mathrm{kcal} / \mathrm{g}$; RAS2: $14.2 \mathrm{kcal} / \mathrm{g}$; RAS3: $12.4 \mathrm{kcal} / \mathrm{g}$ ) y como fuente de proteína tres niveles de harina hidrolizada de pieles de ovino y alpaca - Pioval- $2^{\circledR}(0,3$ y $6 \%$, respectivamente $)$ y tres niveles de harina de soya integral extruida $(0,10$ y $15 \%$, respectivamente). Las vacas estaban al pastoreo sobre cultivo de alfalfa asociado a rye grass y recibieron ensilado de avena. Se determinó la producción diaria de leche (PDL) durante 45 días, así como la densidad (DE), sólidos totales (ST), grasa (GR) y nitrógeno ureico en la leche (NUL) a los $0,15,30$ y 45 días. Las RAS no afectaron la PDL (17.7, 18.8 y $19.0 \mathrm{~kg} /$ día $)$ ni la DE $(1,031,1,031$ y 1,030 $\mathrm{g} / \mathrm{l}$, respectivamente) de la leche. La RAS2 incrementó los ST y GR (13.0\%, 4.2\%) con relación a RAS1 $(12.4 \%, 3.8 \%)$ y RAS3 $(12.2 \%, 3.9 \%)(\mathrm{p}<0.01)$ en la leche, respectivamente. Con la disminución de la fracción energía / proteína en las raciones el NUL aumentó proporcionalmente (RAS1: 28.9; RAS2: 32.3; RAS3: $36.8 \mathrm{mg} / \mathrm{dl} ; \mathrm{p}<0.001)$. En conclusión, el aumento de la fracción energía / proteína de la ración de concentrado no afectó la producción ni la densidad de la leche, pero mejoró el contenido de sólidos totales y grasa; mientras que la reducción de la ratio energía / proteína en la ración incrementó consistentemente el nitrógeno ureico en la leche.
\end{abstract}

Palabras clave: vacas; ración alimenticia; ratio energía / proteína; composición de la leche; NUL

\footnotetext{
${ }^{1}$ Laboratorio de Nutrición y Alimentación Animal, Facultad de Medicina Veterinaria y Zootecnia, Universidad Nacional del Altiplano, Puno, Perú

${ }^{2}$ E-mail:maranibar@unap.edu.pe
}

Recibido: 9 de febrero de 2019

Aceptado para publicación: 2 de octubre de 2019 
This study aimed to determine the effect of the energy / protein ratio of supplementary feed rations (RAS) on the production and characteristics of milk under natural hypobaric conditions ( $4300 \mathrm{~m}$ altitude in Puno, Peru). A total of 24 Brown Swiss cows in first and second third of lactation were distributed in three RAS with three ratios of metabolizable energy / protein (RAS1: $17.0 \mathrm{kcal} / \mathrm{g}$; RAS2: $14.2 \mathrm{kcal} / \mathrm{g}$; RAS3: $12.4 \mathrm{kcal} /$ g) and as a protein source three levels of hydrolysed sheep and alpaca skins - Pioval-2® $(0,3$ and $6 \%$, respectively) and three levels of extruded whole soymeal $(0,10$ and $15 \%$, respectively). The cows were grazing on alfalfa associated with rye grass and supplemented with oat silage. Daily milk yield (DMY) was recorded for 45 days, as well as density (DE), total solids (TS), fat (FA) and milk urea nitrogen (MUN) at 0, 15, 30 and 45 days. The RAS did not affect the DMY $(17.7,18.8$ and $19.0 \mathrm{~kg} /$ day $)$ or the DE $(1.031,1.031$ and $1.030 \mathrm{~g} / 1$, respectively) of the milk. RAS2 increased the TS and FA $(13.0 \%, 4.2 \%)$ in relation to RAS1 $(12.4 \%, 3.8 \%)$ and RAS3 $(12.2 \%, 3.9 \%)(\mathrm{p}<0.01)$ in milk, respectively. The decrease of the energy / protein fraction in the rations increased proportionally the MUN (RAS1: $28.9 ;$ RAS2: 32.3; RAS3: $36.8 \mathrm{mg} / \mathrm{dl} ; \mathrm{p}<0.001$ ). In conclusion, the increase in the energy / protein fraction of the concentrate ration did not affect milk yield or milk density but improved the total solids and fat content; while the reduction of the energy / protein ratio in the ration consistently increased the urea nitrogen in the milk.

Key words: dairy cows; feed ration; energy-protein ratio; milk composition; MUN

\section{INTRODUCCIÓN}

Las regiones del Perú con mayor producción de leche son Arequipa, Cajamarca y Puno; siendo esta última región donde la ganadería lechera se encuentra en constante crecimiento (MINAGRI, 2017), debido al incremento del piso forrajero y a la mejora genética de las vacas. Sin embargo, la primera limitante es la gran variabilidad en la composición nutricional de las pasturas a lo largo del año y la segunda es la alimentación de las vacas con solo forrajes, lo cual resulta insuficiente para cubrir los requerimientos nutritivos para producir leche (Vahmani et al., 2013). Por otro lado, la demanda de nutrientes varía según el peso vivo, nivel de producción y etapa de lactancia, siendo necesario el consumo adecuado de proteína y energía para su óptimo rendimiento (NRC, 2001; Bargo et al., 2002).

La supl ementación proteica y energética en el primer tercio de la lactancia aumentala producción deleche, incluyendo la pro- teína y la grasa en la leche (Brun-Lafleur $e t$ al., 2010; Aghaziarati et al., 2011), mientras que en los dos últimos tercios de la lactación aumenta el nitrógeno ureico en la leche (NUL). La determinación del NUL se ha convertido en una herramienta para asegurar el nivel adecuado de la proteína en la ración y para determinar la eficiencia en la utilización del nitrógeno para producción de leche (Barros et al., 2019). Sin embargo, la eficiencia en la utilización de $\mathrm{N}$ es máxima cuando se combinan altos niveles de energía con bajos niveles de proteína en la dieta (Rius et al., 2010).

Una alimentación con exceso de $\mathrm{N}$ y de baja calidad proteica incrementa la producción de calor y reduce la energía retenida en el cuerpo y la energía bruta de la leche (Reed et al., 2017). Aunque la concentración de $\mathrm{N}$ en sangre y leche están altamente correlacionadas, el NUL está más relacionado con la proteína y la energía en la dieta que con la eficiencia de la utilización del $\mathrm{N}$ o la concentración de amoniaco ruminal (Broderick, 2003). 
Las dietas altas en proteína $(17.3 \%$ en MS) mejoran el consumo de alimento y el rendimiento productivo durante los primeros 150 días de lactancia, mientras que un nivel menor de proteína en la fase final de la lactancia (14.4\% en MS) no afecta negativamente la producción (Law et al., 2009). Las raciones que contienen alrededor de $16 \%$ de proteína y $2600 \mathrm{kcal}$ de EM/kg serían las más adecuadas para una óptima producción lechera y para reducir la excreción de $\mathrm{N}$ al medio ambiente (Broderick, 2003). El NUL es un indicador de la eficiencia del metabolismo de la proteína (Munyaneza et al., 2017) que demuestra que los requerimientos de $\mathrm{N}$ de los microrganismos están asegurados con $12 \mathrm{mg} / \mathrm{dl}$ de NUL, mientras que niveles mayores a $16 \mathrm{mg} / \mathrm{dL}$ indicarían una deficiente utilización del N (Nousiainen et al., 2004).

Debido a que existe una relación directa entre la alimentación y la producción de leche de las vacas, los productores deben proporcionar raciones alimenticias suplementarias (RAS) más nutritivas que los forrajes para mantener una alta producción de leche. En la formulación de las RAS se debe considerar el costo, la producción de leche esperada y la menor eliminación de nitrógeno al medio ambiente (Salo, 2018). En este sentido, los nutricionistas deben buscar el equilibrio entre alcanzar una producción óptima en las vacas y bajar los niveles de urea en la leche. Así, el objetivo del estudio fue determinar el efecto de la suplementación de proteína-energía en vacas Brown Swiss al pastoreo sobre la producción láctea, y la densidad, sólidos totales, grasa y nitrógeno ureico de la leche a fin de maximizar la producción y la calidad de la leche bajo condiciones hipobáricas naturales de la región de Puno.

\section{Materiales y Métodos}

\section{Ubicación}

El estudio se realizó en el fundo Queque Norte de la Ganadera «El Rosario», distrito Santa Rosa, provincia Melgar, región Puno,
Perú. La zona está ubicada en puna seca a una altitud entre 3918 y $4335 \mathrm{~m}$. La temperatura ambiental de la zona durante el periodo experimental fue entre $-10 \mathrm{y}+15^{\circ} \mathrm{C} \mathrm{y}$ la precipitación pluvial entre 5.5 y $18.5 \mathrm{~mm}$.

\section{Animales, Raciones y Alimentación}

De un total de 85 vacas Brown Swiss, se seleccionaron 24 vacas de primer y segundo parto que se encontraban entre el primer y segundo tercio de lactación. Las vacas fueron distribuidas en tres tratamientos, considerando ocho vacas por tratamiento.

Se trabajó con tres raciones alimenticias suplementarias (RAS) con niveles crecientes de la fracción de energía metabolizable-proteína bruta (RAS1: $2225 \mathrm{kcal} / \mathrm{kg}$ $131 \mathrm{~g} / \mathrm{kg}$; RAS2: $2354 \mathrm{kcal} / \mathrm{kg}-166 \mathrm{~g} / \mathrm{kg}$; RAS3: $2431 \mathrm{kcal} / \mathrm{kg}-196 \mathrm{~g} / \mathrm{kg}$ ) y como fuente de energía y proteína se consideraron tres niveles de inclusión de harina hidrolizada de pieles de ovinos y alpacas - Pioval- $2^{\circledR}(0,3$ y $6 \%$, respectivamente) y tres niveles de harina de soya integral extruida $(0,10$ y $15 \%$, respectivamente). La harina Pioval- $2^{\circledR}$ fue obtenida a partir de pieles esquiladas de ovinos y alpacas no aptas para curtiembre. La hidrólisis se hizo a 15 PSI de presión por $2 \mathrm{~h}$. $\mathrm{El}$ análisis químico de la harina se realizó en La Molina Calidad Total Laboratorios de la Universidad Nacional Agraria La Molina (Lima) y contenía $82.9 \%$ de proteína, $9.5 \%$ de extracto etéreo, $9.1 \%$ de cenizas, $0.18 \%$ de calcio, $0.20 \%$ de fósforo, $8.78 \%$ de arginina, $4.89 \%$ de treonina, $0.41 \%$ de triptófano y no se detectaron contenidos de lisina y metionina.

El peso promedio de las vacas para cada tratamiento fue determinado al inicio del experimento (RAS1: $516 \pm 54.5 \mathrm{~kg}$, RAS2: 513 $\pm 63.5 \mathrm{~kg}$; RAS3: $506 \pm 45.1 \mathrm{~kg}$ ). Todas las vacas fueron manejadas bajo un sistema de crianza semi-intensivo con pastoreo en alfalfa y rye grass rotativo en franjas cambiables por la mañana. En la tarde-noche se mantuvieron estabuladas y fueron suplementadas 
Cuadro 1. Composición de las raciones alimenticias suplementarias (RAS) experimentales

\begin{tabular}{|c|c|c|c|}
\hline \multirow{3}{*}{ Ingredientes } & \multicolumn{3}{|c|}{ Nivel de EM (kcal/kg) y PB (\%) } \\
\hline & RAS1 & RAS2 & RAS3 \\
\hline & $2225 / 13.1$ & $2354 / 16.6$ & $2431 / 19.6$ \\
\hline Maíz grano & 25.0 & 20.0 & 18.0 \\
\hline Harina de pescado & 5.0 & 3.0 & 3.0 \\
\hline Harina Pioval-2 ${ }^{\circledR}$ & - & 3.0 & 6.0 \\
\hline Soya integral extruida & - & 10.0 & 15.0 \\
\hline Polvillo de arroz & 5.0 & 5.0 & 5.0 \\
\hline Afrecho de trigo & 20.0 & 20.0 & 17.1 \\
\hline Heno de avena molida & 38.5 & 32.2 & 29.0 \\
\hline Carbonato de calcio & 1.0 & 1.3 & 1.4 \\
\hline Bicarbonato de sodio & 2.5 & 2.5 & 2.5 \\
\hline Fosfato bicálcico & 0.6 & 0.6 & 0.6 \\
\hline Leche Prime $100^{\circledR}$ & 0.3 & 0.3 & 0.3 \\
\hline Premezcla vitamínico-mineral ${ }^{1}$ & 0.1 & 0.1 & 0.1 \\
\hline Arcilla Montchack $^{\circledR 2}$ & 1.0 & 1.0 & 1.0 \\
\hline Sal común & 1.0 & 1.0 & 1.0 \\
\hline Total & 100.0 & 100.0 & 100.0 \\
\hline \multicolumn{4}{|l|}{ Aporte de nutrientes } \\
\hline Materia seca, $\%^{3}$ & 90.8 & 90.9 & 91.1 \\
\hline Energía metabolizable, $\mathrm{kcal} / \mathrm{kg}$ & 2,225 & 2,354 & 2,431 \\
\hline Proteína bruta, $\%^{3}$ & 13.1 & 16.6 & 19.6 \\
\hline Ratio EM kcal/g PB & 17.0 & 14.2 & 12.4 \\
\hline Extracto etéreo, $\%^{3}$ & 3.36 & 5.10 & 6.10 \\
\hline Calcio, $\%$ & 0.94 & 0.97 & 1.02 \\
\hline Fósforo total, \% & 0.64 & 0.63 & 0.63 \\
\hline \multicolumn{4}{|c|}{$\begin{array}{l}\text { Por cada kilogramo de alimento se adicionó: } 30 \text { UI de Vitamina A, } 6.5 \text { UI de Vitamina D3, } 0.022 \text { UI de } \\
\text { Vitamina E, } 25 \mathrm{mg} \text { de Calcio, } 17 \mathrm{mg} \text { de Fósforo, } 1.75 \mathrm{mg} \text { de Magnesio, } 1.8 \mathrm{mg} \text { de Sodio, } 2.8 \mathrm{mg} \text { de Cloro, } \\
0.05 \mathrm{mg} \text { de Azufre, } 0.1 \mathrm{mg} \text { de Cobre, } 0.006 \mathrm{mg} \text { de Cobalto, } 0.22 \mathrm{mg} \text { de Hierro, } 0.1 \mathrm{mg} \text { Manganeso, } 0.003 \\
\mathrm{mg} \text { de Selenio, } 0.009 \mathrm{mg} \text { de Yodo, } 0.28 \mathrm{mg} \text { de Zinc, } 0.028 \mathrm{mg} \text { de Zinc, } 0.010 \mathrm{mg} \text { de Cobre, } 0.001 \mathrm{mg} \text { de } \\
\text { Cobalto, } 0.015 \mathrm{mg} \text { de Manganeso } \\
\text { Arcilla natural del altiplano peruano (Araníbar } \text { et al., 2012) } \\
\text { Valores determinados }\end{array}$} \\
\hline
\end{tabular}

con ensilado de avena y con $3.5 \mathrm{~kg} / \mathrm{vaca} /$ día de cada ración suplementaria (Cuadro 1) después del segundo ordeño y durante 45 días. La utilización de los animales en experimentación contó con la aceptación del comité de ética de la Universidad Nacional del Altiplano.

\section{Mediciones}

El contenido de materia seca (MS), proteína bruta $(\mathrm{PB})$ y extracto etéreo (EE) de las tres RAS fueron analizadas en el Laboratorio de Nutrición Animal de la Facultad de 
Medicina Veterinaria y Zootecnia de la Universidad Nacional del Altiplano, Puno. La producción diaria de leche (PDL) fue registrada en cada ordeño mecanizado (mañana y tarde), utilizando una balanza manual GoldenLark $^{\circledR}$ (China). La producción láctea ( $\mathrm{kg} /$ día) por vaca fue registrada antes de iniciado el experimento y el promedio para 15 días fue de 18.1, 19.9 y $19.6 \mathrm{~kg}$ para RAS1, RAS2 y RAS3, respectivamente.

El muestreo de leche fue realizado cada 15 días $(0,15,30$ y 45$)$ en horas de la mañana (primer ordeño). La leche fue recolectada en frascos estériles y transportados bajo refrigeración $\left(5^{\circ} \mathrm{C}\right)$ para su análisis en el laboratorio. El análisis de densidad (DE, g/l), sólidos totales (ST, \%) y grasa (GR, \%) de la leche se realizó con el equipo Lactoscan $\mathrm{MCC}^{\circledR}$ (Bulgaria), mientras que el análisis de nitrógeno ureico en la leche (NUL, $\mathrm{mg} / \mathrm{dl}$ ) fue realizado con el analizador químico Mindray BS $120^{\circledR}$ (China).

\section{Análisis Estadístico}

Los resultados obtenidos por el efecto de la variable independiente (raciones experimentales) sobre las variables dependientes (PDL, DE, ST, GR y NUL) fueron analizados en un diseño completamente al azar con tres tratamientos y ocho réplicas por tratamiento. En el procesamiento y análisis de datos de los muestreos $(0,15,30$ y $45 \mathrm{~d}) \mathrm{se}$ utilizó el procedimiento Modelo Lineal General (GLM) y la prueba de medias por mínimos cuadrados (LS Means) a $p<0.05$ con el software estadístico Statistical Analysis System (SAS, 2004).

\section{Resultados y Discusión}

\section{Peso Corporal y Producción de Leche}

Los animales presentaron un incremento de peso al final del experimento (RAS1: $34 \pm 22.6 \mathrm{~kg}$; RAS2: $31 \pm 20.4 \mathrm{~kg}$; RAS3: 32 $\pm 9.7 \mathrm{~kg}$ ), pero sin diferencia significativa entre tratamientos. Asimismo, las vacas no mostraron aumento significativo $(\mathrm{p}=0.258)$ en la producción promedio de leche ( $\mathrm{kg} / \mathrm{dí}$ ) durante los 45 días que duró la investigación (Cuadro 2). Estos resultados son concordantes con los reportados por Vargas et al. (2015), quienes indican que las raciones más concentradas no producen aumentos significativos en la producción de leche, mientras que Broderick (2003) y Negi et al. (2015) reportan que el incremento energético de las raciones alimenticias induce un aumento en la producción de leche.

En el estudio de Grainger et al. (2009) aumentando la fuente energética y en el de Winsryg et al. (1991) incrementando la fuente proteica en las raciones de concentrado se encontraron aumentos no significativos en la producción de leche. Contrariamente, Law et al. (2009), incrementando la proteína, y Brun-Lafleur et al. (2010), incrementando las fracciones proteica y energética de las raciones reportaron aumentos en la producción de leche. Estas discrepancias en las investigaciones probablemente se deban a las diferencias en calidad genética, nivel de producción de leche, diferentes sistemas de crianza y medio ambiente.

\section{Densidad}

La densidad de la leche está directamente relacionada con su contenido de grasa, proteína, lactosa y agua. En general la densidad no fue significativamente afectada por la suplementación proteína-energía y se mantuvo entre 1,030 y 1,031 g/l (Cuadro 3). Estos niveles están dentro de los límites óptimos indicados para una leche de buena calidad nutritiva. De hecho, la Norma Técnica Peruana (N.T.P.) 202. 001-2003 (INDECOPI, 2003) indica un rango de $1,029.6$ a $1,034 \mathrm{~g} / 1$ como aceptable.

\section{Sólidos Totales}

El porcentaje de sólidos totales de la leche fue similar entre tratamientos en el día 0 (inicio del estudio); sin embargo, la ración intermedia (RAS2) con $2354 \mathrm{kcal} / \mathrm{kg}$ de EM y 
Cuadro 2. Efecto de la fracción proteína-energía de la ración suplementaria sobre la producción de leche por vaca durante 45 días

\begin{tabular}{lcccc}
\hline \multirow{2}{*}{ Tratamiento } & \multicolumn{3}{c}{ Producción de leche, $\mathrm{kg} /$ día } & Promedio \\
\cline { 2 - 5 } & $0-15$ & $16-30$ & $31-45$ & $0-45$ \\
\hline RAS1 & 18.0 & 17.5 & 17.5 & 17.7 \\
RAS2 & 19.7 & 18.5 & 18.0 & 18.8 \\
RAS3 & 19.4 & 19.1 & 18.5 & 19.0 \\
EEM $^{1}(\mathrm{n}=8)$ & 0.67 & 0.62 & 0.57 & 0.59 \\
P-valor & 0.188 & 0.215 & 0.478 & 0.258 \\
\hline
\end{tabular}

${ }^{1}$ Error estándar de la media con ocho observaciones por media

$16.6 \%$ de PB produjo mayor porcentaje de sólidos totales en la leche al día $30(\mathrm{p}=0.010)$, al día $45(\mathrm{p}=0.007)$ y en el promedio de $15 \mathrm{a}$ 45 días $(\mathrm{p}<0.001)$ respecto a la leche producida por las raciones con la ratio más alta (RAS1) y la ratio más baja (RAS3) de EM/PB (Cuadro 4).

En general, los resultados indican niveles de sólidos totales mayores al $12.1 \%$, los cuales se mantienen dentro del límite establecido por la Norma Técnica Peruana (N.T.P.) 202. 001-2003 que es de $11.4 \%$ (INDECOPI, 2003). Los resultados están de acuerdo con otros investigadores, quienes reportan que el incremento de la fracción proteica (Law et al., 2009; Rius et al., 2010) o el incremento de las fracciones energético - proteica (Brun-Lafleur et al., 2010; Aghaziarati et al., 2011) en las dietas aumentan los componentes de la leche. Así, Broderick (2003) y Negi et al. (2015) encontraron que el incremento de la fracción energética de la dieta aumentó los sólidos totales de la leche. Contrariamente, otros investigadores indican que la suplementación energético - proteica en las raciones no afecta la concentración de sólidos totales de la leche (Castillo et al., 2001; Strusinska et al., 2006; Salado et al., 2011; Vargas et al., 2015).

\section{Grasa}

No se encontraron diferencias en el porcentaje de grasa de la leche por efecto del incremento de energía y proteína en la ración concentrada en los primeros 15 días del estudio. Sin embargo, la leche de las vacas que consumieron la ración intermedia $(2,354$ kcal EM y $16.6 \%$ PB) presentó mayor porcentaje de grasa al día $30(\mathrm{p}=0.022)$, al día $45(\mathrm{p}=0.036)$ y en el promedio de $15 \mathrm{a}$ 45 días $(\mathrm{p}<0.001)$, respecto a la leche de las vacas con raciones de baja y alta ratio $\mathrm{EM} /$ PB (Cuadro 4).

Los resultados sugieren que el componente lipídico de la harina de soya integral extruida y del Pioval-2® tiene capacidad bypass de rumen para ser absorbido en el intestino y de esta forma incrementar la disponibilidad de ácidos grasos para la formación de grasa de la leche. Los resultados concuerdan con los trabajos de Weiss et al. (2009) y Boerman et al. (2015), donde el suplemento graso en la dieta aumenta el porcentaje de grasa de la leche durante las primeras etapas de lactación. El menor contenido de grasa en la leche observado con la RAS3 estaría relacionado con el mayor contenido de proteína de esta ración, ya que la desaminación y la formación de urea en el 
Cuadro 3. Efecto de la fracción proteína-energía de la ración suplementaria sobre la densidad de la leche $(\mathrm{g} / \mathrm{l})$ durante 45 días

\begin{tabular}{|c|c|c|c|c|c|}
\hline \multirow{2}{*}{ Tratamiento } & \multicolumn{4}{|c|}{ Días de muestreo } & \multirow{2}{*}{$\begin{array}{c}\text { Promedio } \\
15-45\end{array}$} \\
\hline & 0 & 15 & 30 & 45 & \\
\hline RAS 1 & 1,031 & 1,031 & 1,031 & 1,030 & 1,031 \\
\hline RAS2 & 1,030 & 1,030 & 1,031 & 1,030 & 1,031 \\
\hline RAS3 & 1,030 & 1,031 & 1,030 & 1,030 & 1,030 \\
\hline $\operatorname{EEM}^{1}(n=8)$ & 0.29 & 0.38 & 0.34 & 0.36 & 0.30 \\
\hline P-valor & 0.760 & 0.884 & 0.234 & 0.867 & 0.831 \\
\hline
\end{tabular}

${ }^{1}$ Error estándar de la media con ocho observaciones por media

Cuadro 4. Efecto de la fracción proteína-energía de la ración suplementaria sobre la composición de la leche durante 45 días

\begin{tabular}{|c|c|c|c|c|c|}
\hline \multirow{2}{*}{ Tratamiento } & \multicolumn{4}{|c|}{ Días de muestreo } & \multirow{2}{*}{$\begin{array}{c}\text { Promedic } \\
15-45 \\
\end{array}$} \\
\hline & 0 & 15 & 30 & 45 & \\
\hline & \multicolumn{5}{|c|}{ Sólidos totales, \% } \\
\hline RAS1 & 12.2 & 12.3 & $12.4^{\mathrm{b}}$ & $12.6^{\mathrm{b}}$ & $12.4^{\mathrm{b}}$ \\
\hline RAS2 & 12.8 & 12.7 & $13.1^{\mathrm{a}}$ & $13.1^{\mathrm{a}}$ & $13.0^{\mathrm{a}}$ \\
\hline RAS3 & 12.4 & 12.3 & $12.3^{\mathrm{b}}$ & $12.1^{\mathrm{b}}$ & $12.2^{\mathrm{b}}$ \\
\hline $\operatorname{EEM}^{1}(n=8)$ & 0.21 & 0.15 & 0.18 & 0.21 & 0.12 \\
\hline \multirow[t]{2}{*}{ P-valor } & 0.170 & 0.131 & 0.010 & 0.007 & 0.001 \\
\hline & \multicolumn{5}{|c|}{ Grasa, \% } \\
\hline RAS1 & 3.5 & 3.6 & $3.8^{\mathrm{b}}$ & $3.9^{\mathrm{b}}$ & $3.8^{\mathrm{b}}$ \\
\hline RAS2 & 3.8 & 3.9 & $4.3^{\mathrm{a}}$ & $4.4^{\mathrm{a}}$ & $4.2^{\mathrm{a}}$ \\
\hline RAS3 & 3.7 & 3.7 & $4.0^{\mathrm{ab}}$ & $3.9^{\mathrm{b}}$ & $3.9^{\mathrm{b}}$ \\
\hline $\operatorname{EEM}^{1}(n=8)$ & 0.15 & 0.10 & 0.13 & 0.15 & 0.07 \\
\hline \multirow[t]{2}{*}{ P-valor } & 0.295 & 0.126 & 0.022 & 0.036 & 0.001 \\
\hline & \multicolumn{5}{|c|}{ Nitrógeno ureico en leche, mg/dl } \\
\hline RAS1 & 28.6 & $30.5^{\mathrm{c}}$ & $30.4^{\mathrm{c}}$ & $25.8^{\mathrm{b}}$ & $28.9^{c}$ \\
\hline RAS2 & 34.4 & $35.1^{\mathrm{b}}$ & $34.2^{\mathrm{b}}$ & $27.8^{\mathrm{b}}$ & $32.3^{\mathrm{b}}$ \\
\hline RAS3 & 29.5 & $40.6^{\mathrm{a}}$ & $37.4^{\mathrm{a}}$ & $32.4^{\mathrm{a}}$ & $36.8^{\mathrm{a}}$ \\
\hline $\operatorname{EEM}^{1}(n=8)$ & 2.26 & 1.09 & 1.29 & 1.50 & 0.92 \\
\hline P-valor & 0.175 & 0.001 & 0.004 & 0.016 & 0.001 \\
\hline
\end{tabular}




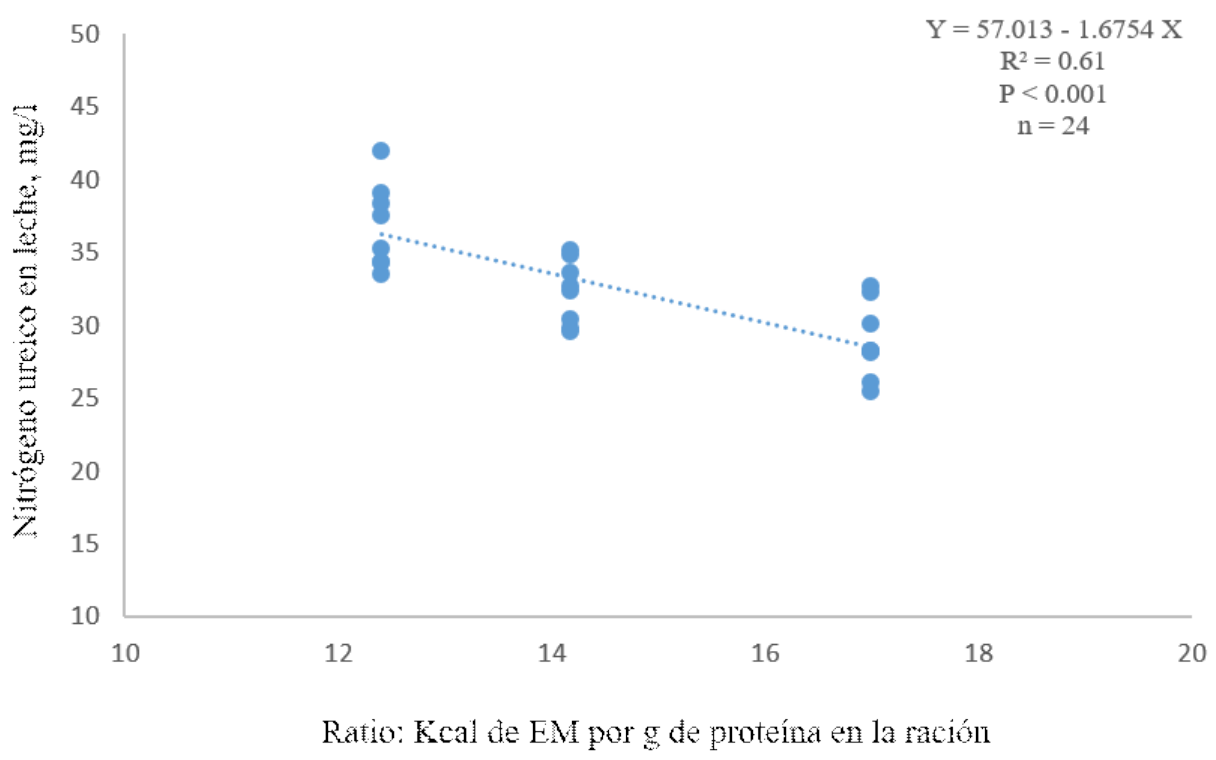

Figura 1. Relación entre la ratio de energía metabolizable $(\mathrm{kcal} / \mathrm{kg})$ y proteína bruta de la ración sobre el contenido de nitrógeno ureico en la leche (NUL)

hígado incrementa el costo energético, obteniéndose como consecuencia menos energía bruta en la leche (Reed et al., 2017).

Los suplementos energético - proteico tienden a incrementar el porcentaje de grasa de la leche (Rius et al., 2010; Brun-Lafleur et al., 2010; Aghaziarati et al., 2011), así como el incremento de la fracción proteica de las raciones durante el primer y segundo tercio de lactación (Law et al., 2009). Contrariamente, Castillo et al. (2001) observaron que niveles crecientes de proteína en las raciones no afectan el porcentaje de grasa en la leche. Así mismo, resultados discrepantes fueron reportados por otros autores quienes encontraron que el suplemento energético en las raciones no afecta el contenido porcentual de grasa en la leche (Broderick, 2003; Grainger et al., 2009; Butler et al., 2010; Salado et al., 2011; Vahmani et al., 2013), mientras que Wattiaux y Grummer (2001) indican que solamente un nivel mayor o igual a $8 \%$ de grasa en la dieta es capaz de inducir cambios en el porcentaje de grasa y en la producción de leche.

\section{Nitrógeno Ureico en Leche (NUL)}

Los valores de NUL fueron similares entre tratamientos al inicio de la investigación (día 0). Durante el experimento, el NUL se incrementó conforme se redujo la ratio energía - proteína en las raciones de concentrado (T1: 28.9; T2: 32.3; T3: $36.8 \mathrm{mg} / \mathrm{dl}$; $\mathrm{p}<0.001$; Cuadro 4). En la Figura 1 se observa la relación entre la ratio energía/proteína en la dieta y el contenido de nitrógeno ureico en la leche $\left(\mathrm{R}^{2}=0.61\right)$, demostrándose que a medida que aumenta el contenido de energía metabolizable por gramo de proteína en las RAS se disminuye el NUL en la leche.

Los valores de NUL del estudio son superiores a los encontrados por Nousiainen et al. (2004), quienes utilizaron un ensilado compuesto de pasto y leguminosa ad libitum y una suplementación de $8.1 \mathrm{~kg} \mathrm{MS} / \mathrm{vaca} /$ día de concentrado a razón de $16.9 \mathrm{kcal}$ de EM/ g de proteína $(2700 \mathrm{kcal} / \mathrm{kg}$ y $160 \mathrm{~g}$ de proteí$\mathrm{na} / \mathrm{kg}$ ) y reportaron un NUL promedio de 13.3 $\mathrm{mg} / \mathrm{dl}(3.8-27.0 \mathrm{mg} / \mathrm{dl})$ para producciones de 
27.8-29.0 kg de leche/vaca/día. Generalmente niveles altos de NUL han sido relacionados con dietas que contienen altos niveles de proteína degradable en rumen y bajos niveles de energía, mientras que niveles bajos de NUL ocurren cuando existe alto contenido de carbohidratos fermentables y bajos contenidos de proteína degradable en rumen (Kebreab et al., 2002; Munyaneza et al., 2017).

La mayor proporción de NUL observado con la RAS3 probablemente se debe a la menor cantidad de energía por gramo de proteína que contiene esta ración (T1: 17.0; T2: 14.2; T3: $12.4 \mathrm{kcal} / \mathrm{g} \mathrm{PB}$, Cuadro 1). Estos resultados también explicarían el menor contenido de sólidos totales y grasa observados en la leche con la RAS3 (Cuadro 4). Como se sabe, tanto la síntesis de proteínas de la leche como el catabolismo del exceso de aminoácidos son acompañados de alto gasto de energía de la dieta (Reed et al., 2017; Salo, 2018). En una investigación, Kebreab et al. (2002) demostraron que el incremento de energía metabolizable de 1.67 a $2.63 \mathrm{Mcal} / \mathrm{kg}$ de alimento en MS redujo significativamente el NUL. Ha sido reportado ampliamente que un incremento de la fracción proteica en el alimento aumenta el NUL (Law et al., 2009; Rius et al., 2010). El contenido de NUL es proporcional al nitrógeno ureico en sangre, por lo que se podría utilizar como un indicador efectivo del estado nutricional y de la eficiencia de utilización del N (Munyaneza et al., 2017).

En cualquier caso, cambios en la concentración del NUL están asociados con cambios en el contenido de proteína - energía en la dieta de las vacas. Una aplicación práctica podría ser realizar el monitoreo del NUL en un establo lechero y seguidamente formular una dieta que maximice el uso de nitrógeno para la producción de leche y minimice la eliminación de nitrógeno al medio ambiente. En la presente investigación y según Roseler et al. (1993) y Broderick (2003), el incremento de la fracción energético - proteica en las raciones alimenticias genera menores con- centraciones de NUL. Si se considera que los valores aceptables de NUL están dentro del rango de 10 a $16 \mathrm{mg} / \mathrm{dl}$ (Munyaneza et al., 2017), entonces los resultados de NUL obtenidos en esta investigación están por encima del doble de urea en la leche, lo cual es nocivo para la salud humana.

\section{Conclusiones}

- El aumento de la ratio energía/proteína de las raciones de concentrado no afectó el nivel de producción láctea ni la densidad de la leche. Sin embargo, los sólidos totales y la grasa de la leche incrementaron con la ración intermedia que contenía $2354 \mathrm{kcal} / \mathrm{kg}$ de EM - 166 $\mathrm{g} / \mathrm{kg}$ de PB (14.2 kcal de EM/g de proteína).

- El incremento de la ratio energía metabolizable / proteína en las raciones experimentales redujo consistentemente la concentración del nitrógeno ureico en la leche, lo que sugiere que vacas de moderada producción láctea deben ser suplementadas con concentrados de niveles intermedios de energía y proteína bajo las condiciones hipobáricas naturales de la región Puno.

\section{Agradecimientos}

Los investigadores manifiestan su agradecimiento al Lic. Jorge Bellido, Gerente General de Ganadera «El Rosario» por su apoyo incondicional en la realización de esta investigación.

\section{Literatura Citada}

1. Aghaziarati $N$, Amanlou $H$, Zahmatkesh D, Mahjoubi E, Yazdi MH. 2011. Enriched dietary energy and protein with more frequent milking offers early lactation cows a greater productive potential. Livest Sci 136: 108-113. doi:10.1016/j.livsci.2010.08.006 
2. Aranibar MJ, Mateos GG, Mamani F, Portocarrero H, Arizabal J, Jara C, Oblitas W, et al., 2012. Arcillas comestibles del altiplano peruano-boliviano. Puno, Perú: Univ. Nacional del Altiplano. 37 p.

3. Bargo F, Muller LD, Delahoy JE, Cassidy TW. 2002. Milk response to concentrate supplementation of high producing dairy cows grazing at two pasture allowances. J Dairy Sci 85: 1777-1792. doi: 10.3168/jds.S00220302(02)74252-5

4. Barros T, Reed KF, Olmos Colmenero JJ, Wattiaux MA. 2019. Milk urea nitrogen as a predictor of urinary nitrogen and urea nitrogen excretions of latelactation dairy cows fed nitrogen-limiting diets. J Dairy Sci 102: 1601-1607. doi: 10.3168/jds.2018-14551

5. Boerman JR, Potts SB, VandeHaar MJ, Lock $A L$. 2015. Effects of partly replacing dietary starch with fiber and fat on milk production and energy partitioning. J Dairy Sci 98: 7264-7276. doi: 10.3168/jds.2015-9467

6. Broderick $\boldsymbol{G A}$. 2003. Effects of varying dietary protein and energy levels on the production of lactating dairy cows. J Dairy Sci 86: 1370-1381. doi: 10.3168/ jds.S0022-0302(03)73721-7

7. Brun-Lafleur L, Delaby L, Husson F, Faverdin P. 2010. Predicting energy $\mathrm{x}$ protein interaction on milk yield and milk composition in dairy cows. J Dairy Sci 93: 4128-4143. doi: 10.3168/jds.20092669

8. Butler ST, de Feu MA, O'Brien B, Guinee TP, Murphy JJ. 2010. Short communication: the effect of dry period duration and dietary energy density in early lactation on the rennet gelation properties of milk. J Dairy Sci 93: 524528. doi:10.3168/jds.2009-2651

9. Castillo AR, Kebreab E, Beever DE, Barbi JH, Sutton JD, Kirby HC, France J. 2001. The effect of energy supplementation on nitrogen utilization in grass silage diets by lactating dairy cows. J Anim Sci 79: 240-246. doi: 10.2527/ 2001.791240x
10. Grainger C, Auldist MJ, O'Brien G, Macmillan KL, Culley C. 2009. Effect of type of diet and energy intake on milk production of Holstein-Friesian cows with extended lactations. J Dairy Sci 92: 1479-1492. doi: 10.3168/jds.2008-1530

11. [INDECOPI] Instituto Nacional de Defensa del Consumidor y Propiedad Intelectual. 2003. Norma Técnica Peruana de la Leche y Productos Lácteos. Leche cruda. Perú: N.T.P.202.001.2003. [Internet]. Disponible en: http:// infolactea.com/wp-content/uploads/ 2015/03/723.pdf

12. Kebreab E, France J, Mills JA, Allison R, Dijkstra J. 2002. A dynamic model of $\mathrm{N}$ metabolism in the lactating dairy cow and an assessment of impact of $\mathrm{N}$ excretion on the environment. $\mathrm{J}$ Anim Sci 80: 248-259. doi: 10.2527/ $2002.801248 \mathrm{x}$

13. Law RA, Young FJ, Patterson DC, Kilpatrick DJ, Wylie ARG, Mayne CS. 2009. Effect of dietary protein content on animal production and blood metabolites of dairy cows during lactation. J Dairy Sci 92: 1827-1827. doi:10.3168/jds.2009-92-4-1827

14. [MINAGRI] Ministerio de Agricultura y Riego. 2017. Estudio de la ganadería lechera en el Perú: análisis de su estructura, dinámica y propuestas de desarrollo. 84 p. [Internet]. Disponible en: http://www.minagri.gob.pe/portal/ analis is-economico/analis is 2018?download=13414: ganaderia-lechera-en-el-peru-2017

15. Munyaneza N, Niyukuri J, El Hachimi Y. 2017. Milk urea nitrogen as an indicator of nitrogen metabolism efficiency in dairy cows: a review. Theriogenology 7: 145-159 doi: 10.5958/ 2277-3371.2017.00032.8

16. [NRC] National Research Council. 2001. Nutrient requirements of dairy cattle. $7^{\text {th }}$ rev. ed. Washington, USA: National Academy Press. p 19-68. [Internet]. Available in: http:// profsite.um.ac.ir/ kalidari/software/ NRC/HELP/NRC\%202001.pdf 
17. Negi D, Mondal BC, Tiwari DP. 2015. Effect of phase-feeding on milk production, milk composition, nutrient utilization and hematobiochemical constituents in lactating crossbred cattle. Anim Nutr Feed Techn 15: 235-244. doi: 10.5958/0974-181x.2015.00026.8

18. Nousiainen J, Shingfield KJ, Huhtanen P. 2004. Evaluation of milk urea nitrogen as a diagnostic of protein feeding. J Dairy Sci 87: 386-398. doi: 10.3168/jds.S0022-0302(04)73178-1

19. Reed KF, Bonfá HC, Dijkstra J, Casper DP, Kebreab E. 2017. Estimating the energetic cost of feeding excess dietary nitrogen to dairy cows. J Dairy Sci 100: 7116-7126. doi: 10.3168/ jds.2017-12584

20. Rius AG, McGilliard ML, Umberger CA, Hanigan MD. 2010. Interactions of energy and predicted metabolizable protein in determining nitrogen efficiency in the lactating dairy cow. J Dairy Sci 93: 2034-2043. doi:10.3168/jds.2008-1777

21. Roseler DK, Ferguson DJ, Sniffen CJ, Herrema J. 1993. Dietary protein degradability effects on plasma and milk urea nitrogen and milk non-protein nitrogen in Holstein cows. J Dairy Sci 76: 525-534. doi: 10.3168/jds.S00220302(93)77372-5

22. Salado EE, Bretschneider G, Scandolo D. 2011. Suplementación de vacas lecheras con niveles crecientes de concentrado: 2 . Peso vivo, condición corporal, metabolitos y hormonas plasmáticas. Rev Argen Prod Anim 31: 109-110.

23. Salo S. 2018. Effects of quality and amounts of dietary protein on dairy cattle reproduction and the environment. $\mathrm{J}$ Dairy Vet Sci 5: 1-7. doi: 10.19080/ JDVS.2018.05.555675
24. SAS Institute. 2004. SAS/STAT ${ }^{\circledR} 9.1$ User's guide. Cary, NC, USA: SAS Institute. $5121 \mathrm{p}$.

25. Strusinska D, Minakowski D, Pysera B, Kaliniewicz, J. 2006. Effects of fatprotein supplementation of diets for cows in early lactation on milk yield and composition. Czech J Anim Sci 51: 196-204.

26. Vahmani P, Fredeen AH, Glover KE. 2013. Effect of supplementation with fish oil or microalgae on fatty acid composition of milk from cows managed in confinement or pasture systems. J Dairy Sci 96: 6660-6670. doi:10.3168/ jds.2013-6914

27. Vargas LI, Lana RP, Modesto JC, Veloso CM, Renno LN, Fonseca DM. 2015. Performance of crossbred cows as a result of energetic and protein supplementation in corn silage based diets. Arq Bras Med Vet Zoo 67: 827836. doi:10.1590/1678-4162-6752

28. Wattiaux MA, Grummer RR. 2001. Guía técnica básica de lechería. Cap. 4. Metabolismo de lípidos en vacas lecheras. USA: Universidad de WisconsinMadison. [Internet]. Disponible en: https:/ /es.scribd.com/doc/71923814/GuiaTecnica-Basica-de-lecheria-Universidad-de-Wisconsin-Madison

29. Weiss WP, Pinos-Rodríguez JM. 2009. Production responses of dairy cows when fed supplemental fat in low- and high-forage diets. J Dairy Sci 92: 61446155. doi: 10.3168/jds.2009-2558

30. Winsryg MD, Arambel MJ, Walters JL. 1991. The effect of protein degradability on milk composition and production of early lactation, somatotropin-injected cows. J Dairy Sci 74: 1648-1653. doi: 10.3168/jds.S00220302(91)78327-6 